\title{
Serum harvested from heifers one month post-zeranol implantation stimulates MCF-7 breast cancer cell growth
}

\author{
WEIPING YE ${ }^{1}$, PINGPING XU ${ }^{1}$, SAIYI ZHONG ${ }^{1}$, WALTER R. THRELFALL ${ }^{2}$, CHRISTOPHER FRASURE $^{3}$, \\ ERIC FENG ${ }^{1}$, HONG LI ${ }^{1}$, SHU-HONG LIN ${ }^{1}$, JIE-YU LIU ${ }^{1}$ and YOUNG C. LIN ${ }^{1,4}$ \\ ${ }^{1}$ Laboratory of Reproductive and Molecular Endocrinology, ${ }^{2}$ Department of Veterinary Clinical Sciences, and \\ ${ }^{3}$ Department of Veterinary Biosciences, College of Veterinary Medicine, The Ohio State University, Columbus OH 43210; \\ ${ }^{4}$ The Ohio State University Comprehensive Cancer Center, Columbus, OH 43210, USA
}

Received August 3, 2010; Accepted September 15, 2010

DOI: $10.3892 /$ etm.2010.155

\begin{abstract}
Breast cancer is a serious disease in the US. Numerous risk factors have been linked to this disease. The safety of using growth promoters, such as zeranol, remains under debate due to the lack of sufficient in vitro and in vivo evidence. Using CellTiter $96^{\mathrm{TM}}$ Aqueous Non-Radioactive Cell Proliferation assay, real-time PCR and Western blot analysis, we evaluated the effects of sera harvested from experimental and control heifers before and after one month of zeranol implantation on the growth of human breast cancer cell line MCF-7 as well as the involved mechanisms. We found that sera harvested from the heifers following one month of zeranol implantation were more mitogenically potent in stimulating the proliferation of MCF-7 cells when compared to sera harvested from the same heifers before zeranol implantation and the control heifers. Further investigation found that dextran-coated charcoal suppressed the stimulating effect of the sera on MCF-7 cell growth. The mechanisms involved in the MCF-7 cell proliferation stimulated by zeranol-containing sera may include up-regulation of cyclin D1 and down-regulation of p53 and p21 expression at the mRNA and protein levels in the cells. The results suggest that the consumption of beef products containing biologically active residues of zeranol or its metabolites is a risk linked to breast cancer development. Further investigation is required in order to clarify this critical issue.
\end{abstract}

\section{Introduction}

Breast cancer remains a serious health issue in the US. It is estimated that more than one-fourth of all cancer patients in 2009 were breast cancer patients, and breast cancer is the

Correspondence to: Dr Young C. Lin, Laboratory of Reproductive and Molecular Endocrinology, College of Veterinary Medicine, The Ohio State University, Columbus, $\mathrm{OH} 43210$, USA

E-mail: lin.15@osu.edu

Key words: breast cancer, beef growth promoter, zeranol, zeranolcontaining serum, cyclin D1, p53, p21 second leading cause of cancer-related mortality. According to clinical cancer statistics, approximately 182,500 new cases are diagnosed each year, with 40,500 patients succumbing to breast cancer in 2009 (1). Epidemiological studies suggest that there are many risk factors associated with breast cancer including age, relative body weight, the number and timing of reproductive events and lactation, exogenous and endogenous hormone concentrations, exposure to radiation, alcohol consumption and family history of breast cancer $(2,3)$. More risk factors are still being discovered.

Zeranol (Z), which is marketed as Ralgro ${ }^{\circledR}$ (MerckSchering-Plough Corp., Kenilworth, NJ, USA), is synthesized from the mycotoxin zearalenone and is a nonsteroidal agent with potent estrogenic activities. It has been widely used as a growth promoter in the US beef feedlot industry to accelerate weight gain, improve feed conversion efficiency and increase the lean meat-to-fat ratio $(4,5)$. Previous investigations revealed that, although $\mathrm{Z}$ has adverse effects on the human breast, the use of $\mathrm{Z}$ as a growth promoter was safe for humans (6). However, the safety of using $\mathrm{Z}$ as a growth promoter has been debated ever since it was approved by the US Food and Drug Administration (FDA). Due to these health concerns, the European Union has banned imports of beef products from animals that have been administered any of the six growth-promoting hormones from the US. Subsequently, the US government challenged the ban with the World Trade Organization in early 1996. Recently, it has received increasing attention due to speculations concerning the possible etiological role of $\mathrm{Z}$ in breast cancer development. Zearalenone and $\mathrm{Z}$ are able to bind to the active site of human estrogen receptor (ER) $\alpha$ and ER $\beta$ in a similar manner as 17 $\beta$-estradiol $\left(E_{2}\right)(7)$. Epidemiological investigation found that the sperm quality in sons of 'high beef consumers' was lower than that in males whose mothers ate less beef during their pregnancy (8).

It has been reported that a higher red meat intake in adolescence increases the risk of premenopausal breast cancer (9). Our laboratory previously reported that $\mathrm{Z}$ was able to transform human normal breast epithelial cells and increase human breast cell growth in a dose-dependent manner (10). $\mathrm{Z}$ has the ability to down-regulate estrogen-regulated human 
breast cancer candidate suppressor gene, protein tyrosine phosphatase $\gamma$ expression (11). More recently, we found that the growth of pre-adipocytes derived from heifer ears implanted for two months with $72 \mathrm{mg} \mathrm{Z}$ was approximately 12-fold faster than that from the control heifers, and the response of the former cells to $\mathrm{Z}$ treatment was more sensitive compared to the latter. Following the investigation, the expression of cyclin $\mathrm{D}$ was found to be up-regulated and p53 down-regulated in the former cells (12). Our preliminary data showed that $2.5 \%$ of Z-containing serum (ZS) harvested from heifers 60 days post $\mathrm{Z}$ implantation (72 $\mathrm{mg}$ ) was capable of transforming human normal breast epithelial cell line MCF-10A to neoplastic breast cancer cells after a 21-day culture. Additionally, we showed that leptin, which plays a role in breast cancer development in obesity, induces human breast cancer epithelial cell sensitivity to Z (13). Therefore, it is crucial to clarify whether the consumption of beef products with residues of biologically active $\mathrm{Z}$ or its metabolites has any relationship with breast cancer.

The present study investigated the effects of biological samples directly harvested from heifers implanted with $\mathrm{Z}$ on the proliferation of the human breast cancer cell line MCF-7 as well as the underlying mechanisms. Our experimental results, for the first time, revealed that sera harvested from the heifers after one month of $\mathrm{Z}$ implantation significantly stimulated MCF-7 cell growth compared to sera harvested from the same heifers before $\mathrm{Z}$ implantation and the control heifers. The stimulatory effect on MCF-7 cells appears to be through the up-regulation of cyclin D1 and down-regulation of p53 and p21 expression at the mRNA and protein levels in MCF-7 cells. Further investigation in primary cultured human normal and cancerous breast epithelial cells is currently in progress in our laboratory. Our results suggest a potential risk of consuming beef products with biologically active $\mathrm{Z}$ or its metabolites in breast cancer initiation, promotion and progression.

\section{Materials and methods}

Animal treatment and blood sampling. The experimental design and sample collection method have been previously described (12). Briefly, $100 \mathrm{ml}$ of blood was harvested from the Z-implanted heifers at day 0 (ZS-D0, prior to Z implantation), and day 30 post-Z implantation (ZS-D30) and from the control heifers at day 0 (NZS-D0) and day 30 (NZS-D30). The sera were immediately transferred to our laboratory and stored at $4^{\circ} \mathrm{C}$ overnight. After the clot from the sides of the tube was carefully loosened using a glass Pasteur, the serum was separated by centrifugation of the blood in a 50-ml centrifuge tube at $4000 \mathrm{rpm}$ for $20 \mathrm{~min}$ at $4^{\circ} \mathrm{C}$. The separated serum was sterilized through a 50-ml conical filter tube (Nalge Nunc International, New York, NY, USA) and stored at $-20^{\circ} \mathrm{C}$. Part of the sterilized ZS-D30 and NZS-D30 was treated with dextran-coated charcoal (DCC, dextran T-70, Sigma; charcoal, Sigma, USA) and stored at $-20^{\circ} \mathrm{C}$.

Cell culture. The MCF-7 cells were purchased from the American Type Culture Collection (ATCC; Manassas, VA, USA) and cultured in phenol red-free Dulbecco's modified Eagle's medium and Ham's F12 medium
$(1: 1) \quad(\mathrm{DMEM} / \mathrm{F} 12) \quad\left(1.05 \quad \mathrm{mM} \quad \mathrm{CaCl}_{2}\right) \quad$ containing $10 \%$ fetal bovine serum (FBS) and an antibioticantimycotic (100 U/ml penicillin $\mathrm{G}$ sodium, $100 \mu \mathrm{g} / \mathrm{ml}$ streptomycin sulfate and $0.25 \mu \mathrm{g} / \mathrm{ml}$ amphotericin B) (Invitrogen, Carlsbad, CA, USA) in a $75 \mathrm{~cm}^{2}$ culture flask in a humidified incubator $\left(5 \% \mathrm{CO}_{2}, 95 \%\right.$ air, $\left.37^{\circ} \mathrm{C}\right)$. When the cells reached $85-90 \%$ confluence, they were subcultured in $75 \mathrm{~cm}^{2}$ culture flasks at a ratio of 1:3 flasks as described above. The cells were dissociated using $3 \mathrm{ml}$ of $0.25 \%$ trypsin-5.3 mM EDTA (Invitrogen) in PBS for $1 \mathrm{~min}$ at $37^{\circ} \mathrm{C}$. The trypsinization was neutralized by the addition of $10 \mathrm{ml}$ of culture medium with $10 \%$ FBS. The dissociated cells were collected and transferred to a $15-\mathrm{ml}$ centrifuge tube and centrifuged at $1200 \mathrm{rpm}$ for 5 min. The supernatant was discarded, and the cell pellets were resuspended in the culture medium with $10 \%$ FBS and subcultured in $75 \mathrm{~cm}^{2}$ culture flasks.

Cell proliferation assay. The MCF-7 cells were seeded into 96-well plates at a density of 3,000 viable cells per well in $100 \mu \mathrm{l}$ DMEM/F12 medium supplemented with 10\% FBS and incubated at $37^{\circ} \mathrm{C}$ overnight. The medium was then replaced with $100 \mu \mathrm{l}$ DMEM/F12 supplemented with $0.2 \%$ bovine serum albumin (BSA, Sigma, USA), and the plate was incubated at $37^{\circ} \mathrm{C}$ for a further $24 \mathrm{~h}$. The cells were then treated with $0.5,2.5$ and $12.5 \%$ ZS-D0 and ZS-D30 or NZS-D0 and NZS-D30 in DMEM/F12 medium supplemented with $0.2 \%$ BSA for $24 \mathrm{~h}$. The cells treated with DMEM/F12 medium supplemented with $0.2 \%$ BSA were the control groups. Treatment of ZS-D30 and NZS-D30 with or without DCC pre-treatment at $0,0.02,0.1,0.5$ and $2.5 \%$ in cultured medium was also carried out. Following $24 \mathrm{~h}$ of treatment, a cell proliferation (MTS) assay was performed as described in the manufacturer's protocol (Promega, Madison, WI, USA).

Cell treatment for RNA isolation and cDNA synthesis. A total of $10^{5}$ viable $\mathrm{MCF}-7$ cells/well were seeded in 6-well plates in $5 \mathrm{ml}$ DMEM/F12 medium with $10 \% \mathrm{FBS}$ and cultured overnight. The medium was replaced with DMEM/ F12 supplemented with 10\% DCC-treated FBS, and the cells were cultured overnight again. Then, MCF-7 cells were treated with $0,0.2,1$ and $5 \%$ of ZS-D0, ZS-D30, NZS-D0 and NZS-D30 in culture medium for $24 \mathrm{~h}$. After treatment, total RNA was isolated from each well using $1 \mathrm{ml} \mathrm{TRIzol}{ }^{\circledR}$ reagent (Invitrogen) according to the manufacturer's instructions. RNA concentration was measured using an ND-1000 spectrophotometer (Thermo Fisher Scientific Inc., USA). RNA $(1 \mu \mathrm{g})$ from each treatment group was reverse transcribed with 200 units M-MLV Reverse Transcriptase (Invitrogen) at $37^{\circ} \mathrm{C}$ for $50 \mathrm{~min}$ and then at $70^{\circ} \mathrm{C}$ for $15 \mathrm{~min}$ in the presence of $1 \mu \mathrm{l}$ $10 \mathrm{mM}$ dNTP (10 mM each dATP, dGTP, dCTP and dTTP at a neutral $\mathrm{pH}$ ) (Invitrogen), $1 \mu 150 \mu \mathrm{M}$ random hexamer (Amersham Bioscience, Buckinghamshire, UK), $10 \mu \mathrm{l} 5 \mathrm{X}$ First Strand buffer, $5 \mu 10.1 \mathrm{M}$ DTT and $1 \mu \mathrm{l}$ RNase inhibitor (Invitrogen) in a total volume of $50 \mu \mathrm{l}$ in a gradient mastercycle (Eppendorf ${ }^{\circledR}$, USA).

Quantitative real-time PCR. Real-time PCR was conducted to measure cyclin D1, p53 and p21 expression. The PCR conditions were optimized for each primer pair and performed in Stratagene Mx3005p (Agilent Technologies, TX, USA). 
A

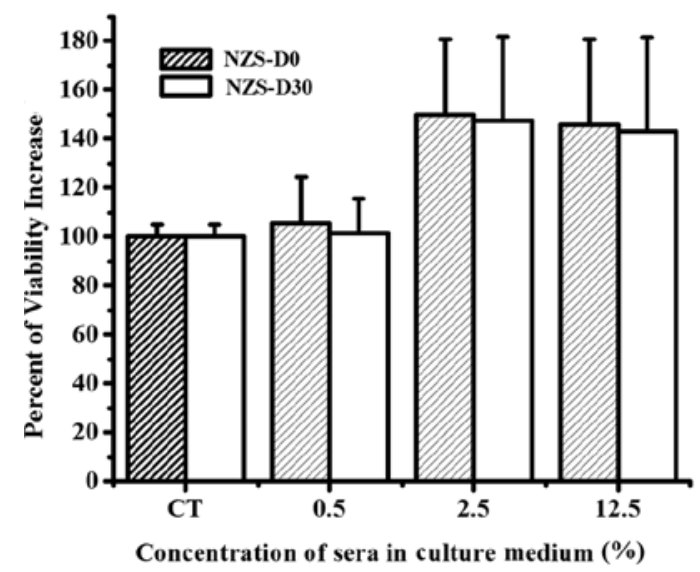

B

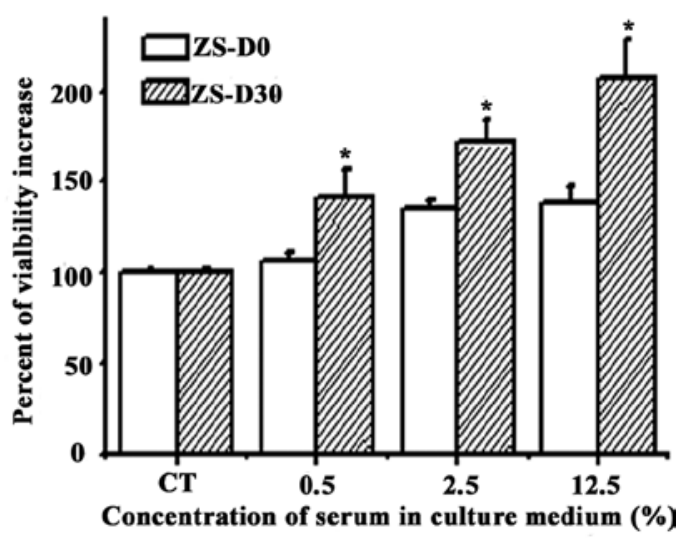

Figure 1. The effects of NZS-D0, NZS-D30, ZS-D0 and ZS-D30 on cell proliferation of human breast cancer cell line MCF-7. (A) Comparison of the effects of NZS-D0 and NZS-D30 on MCF-7 cell growth. No statistical difference was noted between the treatments of the two sera at the same concentration. (B) ZS-D30 was found to be a more potent in stimulating MCF-7 cell proliferation than ZS-D0 at the three concentrations. MCF-7 cells (3,000/well) were treated with different types of sera at concentrations of 0.5, 2.5 and $12.5 \%$ in DMEM/F12 medium for 24 h. Cell proliferation was determined by measuring the optical density at $490 \mathrm{~nm}$ using the MTS assay. Each bar represents the mean \pm SE for 4 replicate wells. *Significant difference of cell growth between ZS-D0 and ZS-D30 at the same concentration.

Newly synthesized cDNA $(2 \mu \mathrm{l})$ was used as a template for the reaction in a total volume of $20 \mu \mathrm{l}$ reactants, which included $10 \mu \mathrm{l}$ of $2 \mathrm{X}$ real-time PCR master mix (Applied Biosystems, Warrington, UK), $3 \mu \mathrm{l}$ ultra-pure water and $5 \mu \mathrm{l}$ of primer mixer. The reactants were first incubated at $95^{\circ} \mathrm{C}$ for $10 \mathrm{~min}$, and then 40 cycles of amplification were carried out with each cycle consisting of denaturing at $95^{\circ} \mathrm{C}$ for $30 \mathrm{sec}$, annealing at $55^{\circ} \mathrm{C}$ for $1 \mathrm{~min}$ and elongation at $72^{\circ} \mathrm{C}$ for $1 \mathrm{~min}$. A dissociation curve was created at the completion of the PCR in order to ensure that the reaction produced the correct products as anticipated. The primer sequences for cyclin D1 were 5'-TTG GTTACAGTAGCGTAG-3' (sense) and 5'-TTATAGTAGC GTATCGTAGG-3' (antisense). The primer sequences for $\mathrm{p} 53$ were 5'-GACAATGGCAGCATCTAC-3' (sense) and 5'-GAA GGTGTAATCAGTCTCC-3' (antisense). The primer sequences for p21 were 5'-GGAAGGAAGCAGGAAGAC-3' (antisense) and 5'-AGCAGAGATACAAGGAAGG-3' (antisense). The primer sequences for 36B4 were 5'-ACATGCTCA ACATCTCCC-3' (sense) and 5'-GCGGCACTTCTCCTGCT CC-3' (antisense). The results of the relative mRNA expression (cyclin D1, p53 and p21 to 36B4) in the MCF-7 cells were analyzed using the $\Delta \Delta \mathrm{Ct}$ method (14).

Western blot assay. The MCF-7 cells were separately seeded in a $100-\mathrm{mm}$ dish $\left(1 \times 10^{6}\right.$ cells/dish) in DMEM/F12 medium supplemented with 10\% FBS and cultured overnight. The medium was then replaced with DMEM/F12 supplemented with DCC-stripped 10\% FBS. After being cultured for $24 \mathrm{~h}$, the cells were treated with $0,0.2,1$ and $5 \%$ of ZS-D30 and NZS-D30 in culture medium for $24 \mathrm{~h}$. Protein extraction, measurement of concentration, separation and Western blot analysis were carried out as previously described (15). For immunoblotting, the following primary antibodies were used: rabbit polyclonal antibodies against cyclin D1, p53 and p21 (Cell Signaling Technology, Inc., Beverly, MA, USA) and goat polyclonal antibody against $\beta$-actin (Santa Cruz Biotechnology, Santa Cruz, CA, USA). The secondary antibody for cyclin D1, p53 and p21 detection was ECL ${ }^{\mathrm{TM}}$ anti-rabbit IgG linked to horseradish peroxidase (Amersham Biosciences, Buckinghamshire, UK) and a donkey anti-goat IgG HRP for $\beta$-actin detection (Santa Cruz Biotechnology). Images were captured using FujiFilm LAS-3000 image system (FujiFilm Medical Systems USA, Inc., TX, USA). The densities of specific bands were quantified by ImageQuant software (Molecular Dynamics, Sunnyvale, CA, USA).

\section{Results}

ZS exhibits stronger stimulation of MCF-7 cell proliferation than NZS. In order to investigate whether ZS exhibits biological activity on MCF-7 cell growth, MCF-7 cells were treated with sera harvested from control and experimental heifers before and after $\mathrm{Z}$ implantation. Following $24 \mathrm{~h}$ of treatment, it was discovered that all the sera stimulated MCF-7 cell growth in a dose-dependent manner as compared to the control group (Fig. 1). No statistical difference was noted between NZS-D0 and NZS-D30 regarding their effects on MCF-7 cell proliferation at the same concentrations (Fig. 1A). However, a significant difference was found between ZS-D0 and ZS-D30 at the same concentration (Fig. 1B). ZS-D30 significantly stimulated the proliferation of MCF-7 cells compared to ZS-D0 at all doses. These data suggest that after one month of $\mathrm{Z}$ implantation, the serum contains certain biologically active components resulting in a more significant effect on the stimulation of MCF-7 cell proliferation.

DCC treatment suppressed the stimulatory effects of ZS-D30 on MCF-7 cell proliferation. In order to confirm whether ZS-D30 contains biological active components, ZS-D30 and NZS-D30 were treated with DCC, which has been reported to effectively strip hormones and growth factors from serum (16), and the effect on MCF-7 cell growth was evaluated. As shown in Fig. 2A, there was no significant difference in the proliferation of MCF-7 cells after treatment with NZS-D30 
A

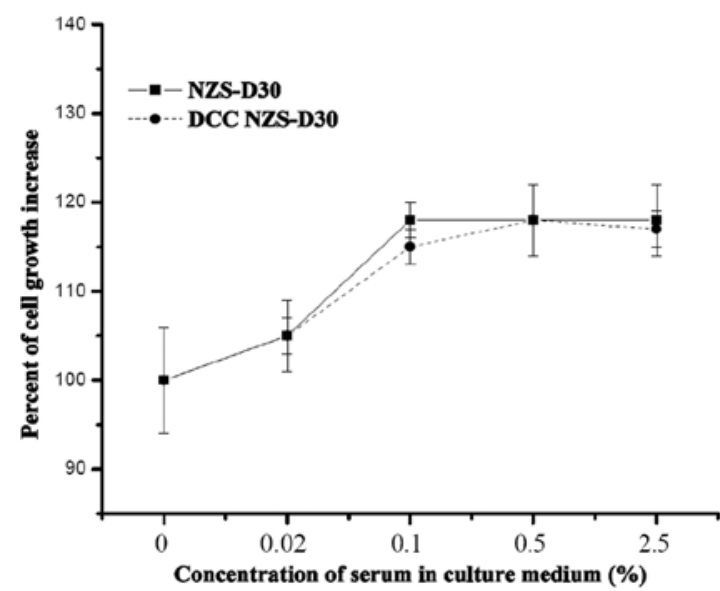

B

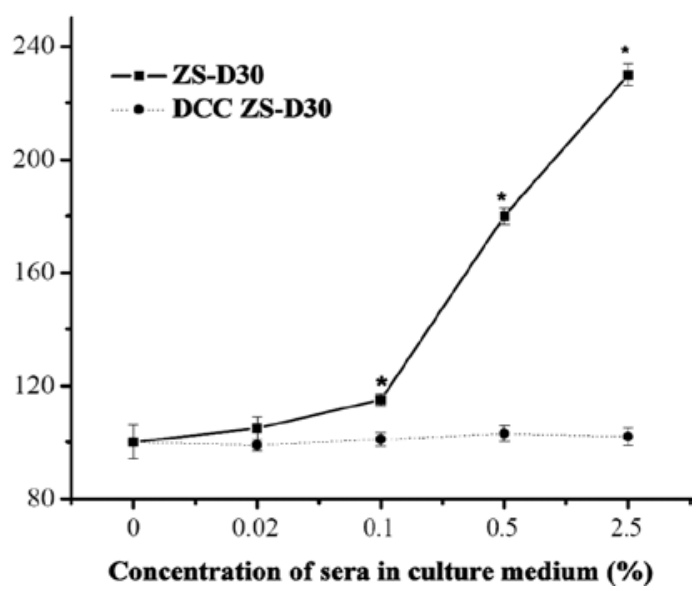

Figure 2. The effects of DCC on MCF-7 cell growth stimulated by NZS-30 and ZS-D30 treatment at 0.2-5.0\% in culture medium. (A) No significant difference was noted between the growth of MCF-7 cells treated by NZS-D30 with and without DCC treatment at the three concentrations. (B) DCC treatment suppressed the stimulatory effect of ZS-D30 on MCF-7 cell proliferation as compared to the sera without DCC treatment.

stripped or not using DCC. However, the ZS-D30 not stripped by DCC significantly increased MCF-7 cell growth, compared to the MCF-7 cells treated with ZS-D30 stripped by DCC. These results revealed that ZS-D30 stripped by DCC removed the biologically active components thus suppressing the stimulatory effects of ZS-D30 on MCF-7 cell growth.

ZS-D30 up-regulates cyclin D1 and down-regulates p53 and p21 mRNA expression in MCF-7 cells. Previous results showed that zearnol treatment regulated the mRNA expression of cyclin D1 and p53 in pre-adipocytes derived from heifers two months after implantation of Z (12). Yuri et al found that treatment with $50 \mathrm{nM} \mathrm{Z}$ accelerated MCF-7 cell growth through down-regulated $\mathrm{p} 21$ expression in the cells (17). To explore the mechanisms involved in MCF-7 cell growth stimulated by ZS-D30, the mRNA expression of cyclin D1, p53 and p21 in MCF-7 cells after treatment with different concentrations of ZS-D30 as well as NZS-D30 was investigated using real-time PCR. Treatment with NZS-D30 for $24 \mathrm{~h}$ did not significantly alter the mRNA expression of cyclin D1, p53 or p21 in MCF-7 cells (Fig. 3). However, ZS-D30 treatment significantly up-regulated cyclin D1 and down-regulated p53 and p21 mRNA in a dose-dependent manner.

ZS-D30 up-regulates cyclin D1 and down-regulates p53 and 221 protein expression in MCF-7 cells. The effects of NZS-D30 and ZS-D30 on the regulation of protein expression of cyclin D1, p53 and p21 in MCF-7 cells was investigated. Following the treatment of MCF-7 cells with $0.2,1$ and 5\% NZS-D30 and ZS-D30 for $24 \mathrm{~h}$, the protein was extracted and Western blot analysis was performed (Fig. 4). Similar to the mRNA expression, the NZS-D30 treatment did not significantly alter the protein expression of cyclin D1, p53 or p21 at the three concentrations. However, ZS-D30 at the three concentrations increased cyclin D1 and down-regulated $\mathrm{p} 53$ and $\mathrm{p} 21$ protein expression in the MCF-7 cells after $24 \mathrm{~h}$ of treatment (Fig. 4). Taken together, the data suggest that the stimulatory effects of ZS-D30 on MCF-7 cell growth may mediate the regulation of cell cycle- related gene expression in the cells. Further mechanisms are yet to be elucidated.

\section{Discussion}

Zeranol has been widely used as a growth promoter in certain countries, including the US and Canada, since it accelerates weight gain, improves feed conversion efficiency and increases the lean meat-to-fat ratio particularly in cattle. A previous investigation found that the use of $\mathrm{Z}$ in cattle was safe for human consumption (18). However, these results were generated using and based on outdated techniques. With the development of molecular biology and medicine, it was demonstrated that these previous findings may be inconclusive. This scenario has previously occurred with diaethylstilbestrol (DES). DES is an estrogen that was approved by the US FDA in 1947 for the prevention of miscarriage and was widely prescribed by doctors in the USA until 1971 and in European countries until the late 1970s (19). Researchers also reported that DES generally increased the weight gain of cattle by $15 \%$ and feed conversion improvement was normally approximately $10 \%$ (20). Additionally, DES increases leanness (20). Due to its growth stimulation and improved feed utilization, orally administered DES for cattle was approved by the US FDA in 1954. Later, an investigation found that DES was not only associated with cancer in women to whom DES was prescribed during their pregnancy, but also in their daughters (21-23). These findings led the FDA to remove oral DES for cattle from the market in 1972 and implants the following year. A previous investigation among workers occupationally exposed to $\mathrm{Z}$ was conducted due to a variety of reported breast symptoms, including sharp pain, tingling, burning, aching and irritation. In addition, two former workers (one male, one female) had boys aged under 5 years who developed gynaecomastia and presented unusual growth spurts. These two boys were exposed to $\mathrm{Z}$ through their parents workclothes. The symptoms in the two boys abated after their parents changed work to control the $\mathrm{Z}$ exposure (6). The investigation clearly illustrated the relationship between breast symptoms and exposure to Z, particularly in children since they 
A
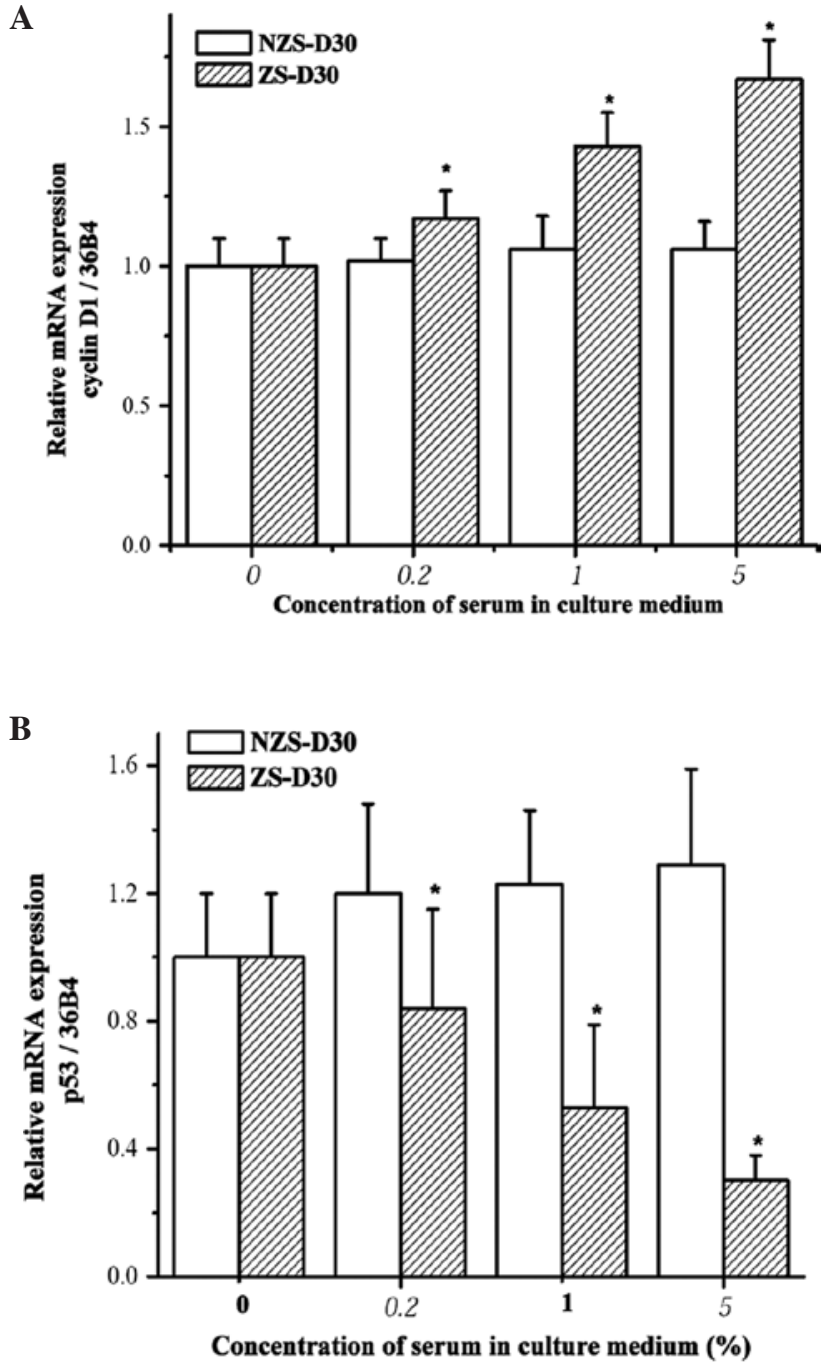

C

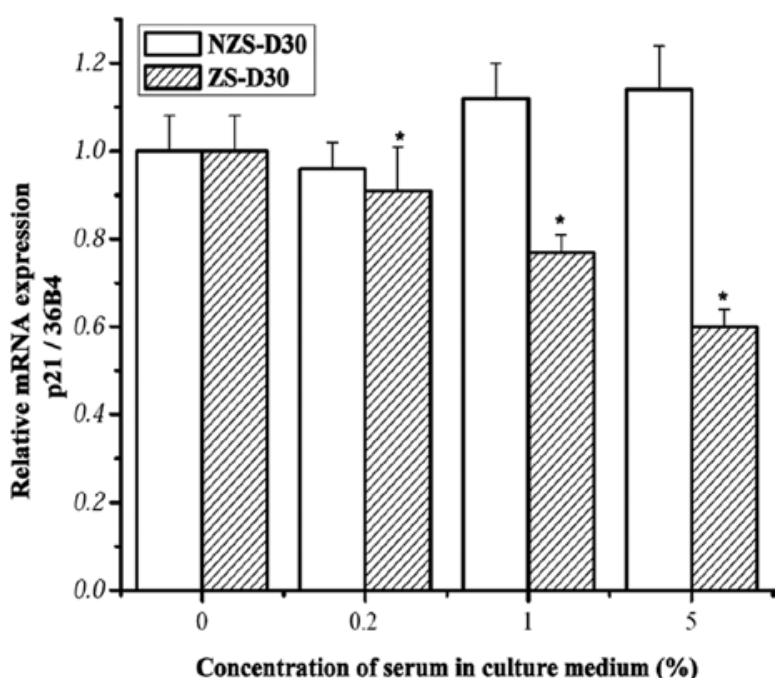

Figure 3. Comparison of the effects of NZS-D30 and ZS-D30 on the regulation of the mRNA expression of cyclin D1, p53 and p21 in MCF-7 cells after $24 \mathrm{~h}$ of treatment. (A) The expression level of cyclin D1 mRNA in MCF-7 cells after being treated with $0.2-5 \%$ of NZS-D30 and ZS-D30 in cultured medium for $24 \mathrm{~h}$. The expression of cyclin D1 mRNA was up-regulated by treatment with ZS-D30 when compared to expression after treatment with NZS-D30. (B) Treatment of ZS-30 at $0.2-5.0 \%$ in culture medium significantly down-regulated the expression levels of p53 mRNA in MCF-7 cells compared to that of NZS-D30. (C) The expression of p21 mRNA in MCF-7 cells was significantly suppressed by treatment with ZS-D30 at three concentrations compared to expression after treatment with NZS-D30.

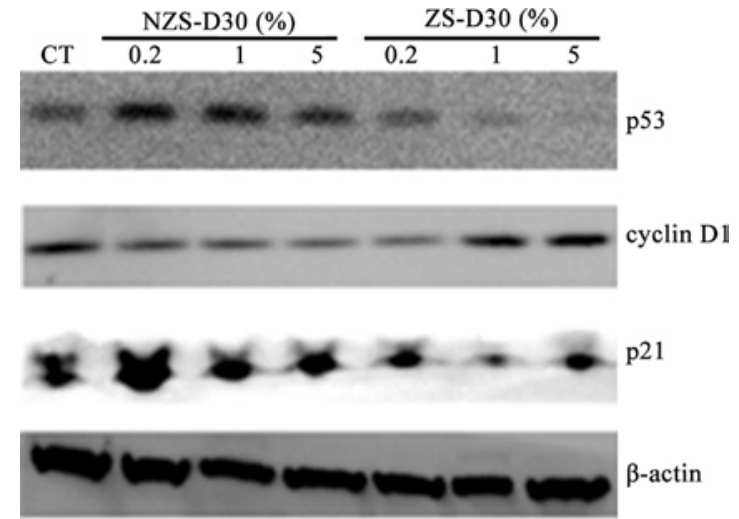

Figure 4. Regulatory effect of NZS-D30 and ZS-D30 on the expression levels of cyclin D1, p53 and p21 protein in MCF-7 cells. The MCF-7 cells were treated with both NZS-D30 and ZS-D30 at $0.2,1$ and 5\% in culture medium for $24 \mathrm{~h}$. The protein was extracted and then Western blot analysis was performed. $\beta$-actin was used as an internal control. The results show that cyclin D1 protein expression in MCF-7 cell was increased by treatment with ZS-D30, while the expression levels of p53 and p21 protein were downregulated by ZS-D30 in a dose-dependent manner as compared to levels after NZS-D30 treatment.

may be more sensitive to $\mathrm{Z}$ than adults. Human exposure to $\mathrm{Z}$ occurs through ingestion of beef products that contain pharmacological active residuals or its metabolites. Current research is raising concerns regarding the relationship between the consumption of beef products and adverse health risks associated with breast cancer development. Our previous data revealed that pre-adipocytes derived from heifers two months post-Zimplantation were sensitive to $\mathrm{Z}$ treatment. This prompted us to investigate whether biological samples such as serum and meat extracts harvested from the heifers after $\mathrm{Z}$ implantation have an effect on human breast cancer cell growth.

The present study revealed that the sera harvested from the heifers one month post-Z implantation significantly stimulated MCF-7 cell proliferation compared to the sera harvested from the same heifers prior to $\mathrm{Z}$ implantation as well as that from the control heifers. The results imply that the residues of biologically active $\mathrm{Z}$ or its metabolites contained in the sera exhibit a stimulatory effect on MCF-7 cells, and their activities can be suppressed by DCC treatment. The preliminary data also showed that the muscle extracts derived from the heifers one month post-Z implantation stimulated MCF-7 cell proliferation. We detected $\mathrm{Z}$ concentrations in the muscles, and the concentrations in sera will be detected using ELISA method once its antibody has developed. It is difficult to claim that the consumption of beef products with residues of biologically active $\mathrm{Z}$ or its metabolites is a risk factor in breast cancer. More evidence is required in order to clarify this crucial health issue. Further investigation of the impacts of biologically active $\mathrm{Z}$ and its metabolites on primary cultured human normal breast epithelial cells, stromal cells, pre-adipocytes and stem/progenitor cells is in progress in our laboratory.

Cell cycle regulation plays a very important role in mammary gland development and carcinogenesis. Numerous researchers have found that cyclin D1, p21 and p53 are associated with cell cycle regulation in breast cancer initiation, promotion and progression. Cyclin D1 is one of the most frequently overexpressed proteins and one of the most 
commonly amplified genes in breast cancer $(24,25)$. It is able to regulate the growth of estrogen-responsive tissues by activating the estrogen receptor in a ligand-independent manner (26). The tumor suppressor p53 is able to regulate cell proliferation and apoptosis. An imbalance between cell proliferation and apoptosis results in a rapid increase in cell numbers, the most prominent characteristic of tumors. Normal breast epithelial cells induce p53-dependent apoptosis and p53-independent cell cycle arrest of breast cancer cells (27). Tumor angiogenesis is considered a multi-pathway process, while p21 (WAF1/CiP1) is a cyclin-dependent kinase inhibitor involved in cell division and survival. It is activated by p53 and is a downstream effector for p53 function by inducing $\mathrm{G} 1$ arrest when normal breast cells are exposed to DNA-damaging agents (28). The expression of the p21 gene has been found to be regulated by estrogen in estrogen receptor-positive human breast cancer cells (29).

We demonstrated that ZS-D30 increased cyclin D1 and down-regulated p53 and p21 expression in MCF-7 cells at the mRNA and protein levels, when compared to NZS-D30. This may partially explain why ZS-D30 significantly stimulated MCF-7 cell proliferation. Other mechanisms involved in cell cycle regulation may also exist, but further investigation is required to elucidate them. The data show that certain as yet undefined growth factors that are responsible for the stimulatory action of MCF-7 cell proliferation may be secreted into the blood circulation of heifers upon $\mathrm{Z}$ implantation. We attribute the stimulatory effect of ZS on MCF-7 cell growth to the implantation of $\mathrm{Z}$.

In conclusion, sera directly harvested from heifers one month post-Z implantation exhibited a potent stimulatory effect on MCF-7 cell growth that was mediated through an increase in cyclin D1 and a decrease in p53 and p21 expression at the mRNA and protein levels. Our results, to a certain degree, suggest the association between the biological samples derived from heifers implanted with $\mathrm{Z}$ and the potential adverse health risk of breast cancer. We require further evidence to clarify this critical health issue.

\section{Acknowledgements}

We thank Dr Walter R. Threlfall and his team members for collecting the biological samples from the control and experimental heifers. We also thank manager Martin Mussard and his team members for taking care of the heifers in the beef cattle barn located in the Ohio State University Livestock Facilities. This research was supported by NIH Grant R01 ES 015212.

\section{References}

1. Jemal A, Siegel R, Ward E, et al: Cancer statistics, 2009. CA Cancer J Clin 59: 225-249, 2009.

2. Brekelmans CT: Risk factors and risk reduction of breast and ovarian cancer. Curr Opin Obstet Gynecol 15: 63-68, 2003.

3. Delort L, Satih S, Kwiatkowski F, et al: Evaluation of breast cancer risk in a multigenic model including low penetrance genes involved in xenobiotic and estrogen metabolisms. Nutr Cancer 62: 243-251, 2010.

4. Thonney ML: Growth, feed efficiency and variation of individually fed Angus, polled Hereford and Holstein steers. J Anim Sci 65: 1-8, 1987.

5. Prichard DL, Hargrove DD, Olson TA, et al: Effects of creep feeding, zeranol implants and breed type on beef production: I. Calf and cow performance. J Anim Sci 67: 609-616, 1989.
6. Aw TC, Smith AB, Stephenson RL, et al: Occupational exposure to zeranol, an animal growth promoter. Br J Ind Med 46: 341-346, 1989.

7. Takemura H, Shim JY, Sayama K, Tsubura A, Zhu BT and Shimoi K: Characterization of the estrogenic activities of zearalenone and zeranol in vivo and in vitro. J Steroid Biochem Mol Biol 103: 17-7, 2007.

8. Swan SH, Liu F, Overstreet JW, et al: Semen quality of fertile US males in relation to their mothers' beef consumption during pregnancy. Hum Reprod 22: 1497-1502, 2007.

9. Linos E, Willett WC, Cho E, et al: Red meat consumption during adolescence among premenopausal women and risk of breast cancer. Cancer Epidemiol Biomarkers Prev 17: 2146-2151, 2008.

10. Liu S and Lin YC: Transformation of MCF-10A human breast epithelial cells by zeranol and estradiol-17beta. Breast J 10: 514-521, 2004.

11. Liu S, Sugimoto Y, Kulp SK, et al: Estrogenic down-regulation of protein tyrosine phosphatase gamma (PTP gamma) in human breast is associated with estrogen receptor alpha. Anticancer Res 22: 3917-3923, 2002

12. Ye W, Xu P, Threlfall WR, et al: Zeranol enhances the proliferation of pre-adipocytes in beef heifers. Anticancer Res 29: 5045-5052, 2009.

13. Xu P, Ye W, Jen R, et al: Mitogenic activity of zeranol in human breast cancer cells is enhanced by leptin and suppressed by gossypol. Anticancer Res 29: 4621-4628, 2009.

14. Livak KJ and Schmittgen TD: Analysis of relative gene expression data using real-time quantitative PCR and the 2(-Delta Delta C(T)) method. Methods 25: 402-408, 2001.

15. Ye W, Chang HL, Wang LS, et al: Modulation of multidrug resistance gene expression in human breast cancer cells by (-)-gossypol-enriched cottonseed oil. Anticancer Res 27: 107-116, 2007.

16. Darbre P, Yates J, Curtis S, et al: Effect of estradiol on human breast cancer cells in culture. Cancer Res 43: 349-354, 1983.

17. Yuri T, Tsukamoto R, Miki K, et al: Biphasic effects of zeranol on the growth of estrogen receptor-positive human breast carcinoma cells. Oncol Rep 16: 1307-1312, 2006.

18. Kuiper-Goodman T, Scott PM and Watanabe H. Risk assessment of the mycotoxin zearalenone. Regul Toxicol Pharmacol 7: 253-306, 1987.

19. Giusti RM, Iwamoto K and Hatch EE: Diethylstilbestrol revisited: a review of the long-term health effects. Ann Intern Med 122: 778-788, 1995.

20. Dinusson WE, Andrews FN and Beeson WM: The effects of stilbestrol, testosterone, thyroid alteration and spaying on the growth and fattening of beef heifers. J Anim Sci 9: 321-330, 1950.

21. Andrews FN, Beeson WM and Harper C: The effect of stilbestrol and testosterone on the growth and fattening of lambs. J Anim Sci 8: 578-582, 1949.

22. Beral V and Colwell L: Randomised trial of high doses of stilboestrol and ethisterone in pregnancy: long-term follow-up of mothers. Br Med J 281: 1098-1101, 1980.

23. Herbst AL, Ulfelder $\mathrm{H}$ and Poskanzer DC: Adenocarcinoma of the vagina. Association of maternal stilbestrol therapy with tumor appearance in young women. New Eng J Med 284: 878-881, 1971.

24. Ellis PE, Maclean AB, Crow JC, et al: Expression of cyclin D1 and retinoblastoma protein in Paget's disease of the vulva and breast: an immunohistochemical study of 108 cases. Histopathology 55: 709-715, 2009.

25. Millar EK, Dean JL, McNeil CM, et al: Cyclin Dlb protein expression in breast cancer is independent of cyclin D1a and associated with poor disease outcome. Oncogene 28: 1812-1820, 2009.

26. Zwijsen RM, Buckle RS, Hijmans EM, et al: Ligand-independent recruitment of steroid receptor coactivators to estrogen receptor by cyclin D1. Genes Dev 12: 3488-3498, 1998.

27. Toillon RA, Chopin V, Jouy N, et al: Normal breast epithelial cells induce p53-dependent apoptosis and p53-independent cell cycle arrest of breast cancer cells. Breast Cancer Res Treat 71: 269-280, 2002.

28. Brugarolas J and Jacks T: Double indemnity: p53, BRCA and cancer. p53 mutation partially rescues developmental arrest in Brca1 and Brca2 null mice, suggesting a role for familial breast cancer genes in DNA damage repair. Nat Med 3: 721-722, 1997.

29. Mandal S and Davie JR: Estrogen regulated expression of the p21 Waf1/Cip1 gene in estrogen receptor positive human breast cancer cells. J Cell Physiol 224: 28-32, 2010. 